\title{
A Community Based Study on Care Practice and Attitudes on male Circumcision in Muslim Community of Arghakanchi District, Nepal
}

\author{
Mohan Paudel $^{1}$, Suresh Mehata ${ }^{2}$
}

\begin{abstract}
:
Male circumcision is an obligatory religious or puberty rite among Muslims, Jews, Africans, and some other peoples. When, where, how, and by whom the operation is performed vary from group to group. The study was conducted in Pali VDC of Arghakhanchi district. Pali VDC is situated about 22 kilometers in the east from Sandhikharka, the headquarter of the district. It covers about 125 hectors land and is divided into 9 wards. It has 5500 populations in an average. There is one secondary school, one lower secondary school and two primary schools. The Muslim population resides entirely in ward no-1, 2, 3 \& 4 of the VDC.

The practices regarding circumcision and health seeking behaviour seems not very satisfactory as the practice so far has not been conducive to health of the children. This has been carried out nearly $100 \%$ by Hazam who is not health worker and hospitalization of circumcision is almost absent. Only small proportion of cases of circumcision (22\%) during post circumcision period have sought for health institutions. However, looking at the use of modern medicines (injections/ tablets/capsules) during circumcision by about $23 \%$ shows the hope for improvement. People's attitudes regarding circumcision seems far better than the practices that are currently prevalent in the community. The higher share of people in favor of hospitalization (91\%) and the opinions of majority (62\%) as health workers the appropriate decision maker makes the sign of possible intervention program to be successful.
\end{abstract}

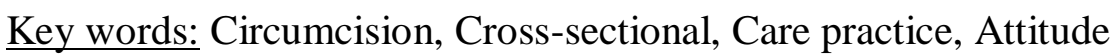

\section{Introduction}

Male circumcision is an obligatory religious or puberty rite among Muslims, Jews, Africans, and some other peoples. When, where, how, and by whom the operation is performed vary from group to group. Circumcision is not practiced by about $80 \%$ of the world's population, including most residents of continental Europe and Asia (except Muslims), and most residents of the Western Hemisphere south of the Rio Grande. ${ }^{2}$

Originally, it is likely that no health claims were attributed to circumcision. Millennia later, however, Herodotus, Philo, and other ancient Greeks suggested that the practice might have hygienic benefits, although it was not adopted by the Greeks. In the late 19th century, circumcision came to be viewed in English-speaking countries as a panacea to stop masturbation, which was thought to cause many illnesses. The American physician, P. C. Remondino in his once highly regarded and often-quoted book History of Circumcision From the Earliest Times to the Present (1891), claimed that circumcision prevented or cured about 100 ailments, including among them alcoholism, epilepsy, hernia, and lunacy. ${ }^{2}$

Circumcision is a universal practice, which is greatly influenced by cultural and religious traditions, especially of the Muslims and Jews. It is the most frequent operation on males not only in Islamic countries, but also other parts of the world. For example, in the United States

\footnotetext{
${ }^{1}$ Institute of Medicine, TU, Katmandu

${ }^{2}$ MMIHS, Nakhu, Lalitpur.
} 
of America more than one million male infants are circumcised each year. The performance of circumcision is one of the rules of cleanliness in Islam.

The Prophet Muhammad recommended performing circumcision at an early age. Al-Mawardi (one of the Islamic scholar) stated that the chosen time is the 7th day after birth, but it can be carried out up to 40 days after birth or thereafter until the age of 7 years, depending upon the health of the infant or child at the time. 3 The Koran contains no specific ordinance on this subject. Currently, approximately one-sixth of the world's male population is circumcised mostly on religious grounds. In Western societies circumcision is performed for medical reasons, the commonest of which is phimosis. ${ }^{4}$

There is evidence to suggest that hygiene may be one reason, as appears to be the case for elite classes in ancient Egypt and the Aztec peoples Ritualistic circumcision has been practiced in West Africa for more than 5000 years and in the Middle East for over 3000 It is virtually universal in the Jewish and Muslim religions. ${ }^{5}$

In most Islamic societies, boys are circumcised not as infants but instead between the ages of 2-14. On a social level, circumcision is considered as the religious introduction of a child into his society as well as an important step for the transition to manhood. This is also the main reason why the circumcision ceremony (which can be quite an elaborate affair depending on the financial means of the parents) is postponed until the child can appreciate the significance of the procedure. ${ }^{6}$

The practice of male circumcision as a medical procedure started in the late 19th century. Previously, the practice of circumcision was exclusively a religious practice without any claim of medical benefit. ${ }^{7}$

\section{Methodology}

The study was conducted in Pali VDC of Arghakhanchi district. Pali VDC is situated about 22 kilometers in the east from Sandhikharka, the headquarter of the district. It covers about 125 hectors land and is divided into 9 wards. It has 5500 populations in an average. There is one secondary school, one lower secondary school and two primary schools. The Muslim population resides entirely in ward no-1, 2, $3 \& 4$ of the VDC.

The target population of the study was all the Muslim households of the VDC and Muslim households outside the VDC esp. of mountainous part like Gorham, Pyuthan, Tanahu and others that have the similar cultural background and practices.

Interview of survey questionnaires with the community people and guideline for natural group discussion

Semi-structured interview for quantitative data was taken by the interrogators and me from the community. Father of the child will be first target of respondents and in his absence child's mother, grandfather and any other members of his family with age above 15 years respectively. Natural group discussion was conducted in two different occasions with necessary guidelines among participants of teashop and at a Chautara (a place where people usually gather for chatting ) of Muslim community.

\section{Results}

About $33 \%$ of the respondents fell in age group 15-35 and about $39 \%$ of the respondents were in age group 36-45 years. About $28 \%$ of the respondents were with the age above 55 years. About $13 \%$ of the respondents were illiterate and rest were literate. Among literate, majority (About $55 \%$ of the respondents had got primary level education. There were only about $10 \%$ 
respondents with the qualification equal to SLC or above it. Looking at the occupational status among the respondents, $58 \%$ were farmers, $28 \%$ of the respondents have engaged in business and $11 \%$ of the respondents were service holders. As per the respondents, about $78 \%$ of their youngest children were circumcised during 13-36 months of their age. Eight percentages of the children were circumcised during their first year of life, $14 \%$ of the children were circumcised during 37-60 months of their age. Regarding the place of circumcision, $86 \%$ of the children as reported by respondents were circumcised at home and remaining 14\% were circumcised at Masjit / Mothersa ( holy place where Muslims learn about their religion, pray for Allah ). None was circumcised in Health Institution ( $\mathrm{HI}$ )/hospital. Regarding the decision at circumcision, decision for $45 \%$ of the children was made by Hazam. For about $27 \%$ of the children the decision was made by their parents and joint decision (Hazam and Father/Mother) was made for circumcision of $25 \%$ of the children.

Three children were circumcised using new blades (4.2\%) whereas rest of the children i.e. 61 children ( $95.4 \%$ ) were circumcised using knife as per the respondents' opinion. About $67 \%$ used ash and ghee mixed for healing of circumcised wound and about $17 \%$ used Moso and ghee mixed in the operated part. Only ash was used for about $14 \%$ of the children. Only about $5 \%$ of circumcised children got medicinal ointments in their circumcised wound.

While asking about medication ( oral tablet/capsule/injection ), about $77 \%$ of the respondents mentioned that their children were not given any medication ( oral tablet/capsule/injection ). Only about $23 \%$ of the respondents stated that their children were under medications ( oral tablet/capsule/injection ). Regarding the post circumcision complications, $39 \%$ of the respondents mentioned their children went through the complications while remaining all responded that their children didn't have to suffer any complications after circumcision was performed. Regarding the management of post circumcision complications, complications were manage by home treatment for about $78 \%$ of the children as state by respondents and about $22 \%$ of the children were managed under health institutions. It took less than 5 days for about $3 \%$ of the children to heal their wound. About $31 \%$ were got the wound healed within 6 to 10 days. For about $13 \%$ of children it took about two months and for about $14 \%$ of the children the time taken for healing of wound was more than two months.

Regarding the benefits of circumcision, about $33 \%$ of the respondents said that they could be religiously healthy doing circumcision. Eleven percentages of the respondents said it as a hygienic method. About $9 \%$ of the respondents mentioned sexual satisfaction as its benefit. About 38\% said both religiously healthy and hygienic method while about $9 \%$ mentioned all the three benefits (religiously healthy, hygienic method and sexual satisfaction).

The reason for circumcision, about $44 \%$ of the respondents stated religious faith as the cause for circumcision. About $9 \%$ of the respondents said tradition and about 5\% said compulsion as the reason for circumcision. About $31 \%$ stated both religious faith and tradition as the reasons for circumcision. Thirty-nine percentage of the respondents mentioned during two years of child age, it is better to circumcise. About $34 \%$ of the respondents said 3 years of child' age as appropriate age for circumcision. Regarding the respondents' opinion on appropriate decision maker for circumcision, about $62 \%$ mentioned health personnel, about 16\% mentioned Father /Mother and remaining 22\% said Hazam as their appropriate decision maker for whether to circumcise child at the moment. Regarding the appropriate circumciser on respondents' opinion, about $86 \%$ of the respondents preferred for health personnel and remaining $13 \%$ preferred for Hazam/Naun for circumcising their children. Regarding their 
opinion on hospitalization, about $91 \%$ were agree about hospitalization of children for circumcision. Only nine percentages of respondents didn't hospitalization for circumcision. Many of the respondents said that hospitalization is beneficial because of quick healing of wound there, availability of medicines and quality services availability, facilities for sterilization too. There were about $48 \%$ of the respondents agreed to have circumcision facilities/services from both categories of health workers whereas $51.2 \%$ i.e. 30 respondents were in favour of Muslim health workers. While probing on how they take circumcision, about $47 \%$ of the respondents stated circumcision as a must do religious work, $28 \%$ of the respondents mentioned circumcision as their tradition and $8 \%$ of the respondents perceived circumcision as festival.

\section{Discussion}

In all the 64 sampled households, the respondents were male with different ages ranging from 15 years to 73 years. About $28 \%$ were found with age above 55 years. Respondents of about $13 \%$ of the households were illiterate while rests of all were literate with majority having primary level education only. Respondents in about $58 \%$ of the households reported agriculture as their occupation, while $28 \%$ of the households reported business as their occupation.

Education plays key role in care practices, attitude and knowledge regarding circumcision. Only $9 \%$ of the households with the respondents having degree of SLC or above may become a challenge to raise awareness and thus to make this practice more aseptic and healthy within a limited time frame. Several other prevalence and comparison studies taking individuals ( married, unmarried, circumcised, uncircumcised ) as unit of analysis have been done before in different Muslim world and African countries.

Regarding care practices and health seeking behaviors, this study shows that majority of children are circumcised during two and three years of their age. A community based study conducted in Philippines showed that majority were circumcised between ages 10 and 14 years. Similar study done in South Korea showed that out of total 1306 circumcised men in the study sample, $15 \%$ were circumcised at age $>15$ days.

Regarding decision maker, study shows Hazam as decision maker (solely or partially) as reported in about $72 \%$ of the reported households. While a community based study conducted in South Korea showed father/ mother as decision maker for about $67 \%$ of the men out of sample total (1306 circumcised)[6] Through individual as well as natural group discussion, nobody in the sampled households was found to object circumcision. As reported by participants, nobody remains uncircumcised.

All the respondents in each households stated that home/ Masjit were the place of circumcision for their children. Through natural group discussion, it was found that in cities and especially among wealthy Muslims now the children are taken in hospital.

Study found that respondents in $96 \%$ of the household reported use of Knife by Hazam for circumcision. Natural group discussion found that the knife was not sterilized; the same single knife was used for many children just after gentle ringing with lukewarm water. 
Not to seek health worker for circumcision might be because of their rigid religious beliefs and low awareness about possible harms and dangers of the practice to child's health.

Study explored that respondents in about $39 \%$ of households reported any of the complications (infection, swelling, bleeding). Several other studies done in other countries have also showed at least $20 \%$ of the circumcised children/ men suffer from complication. For management of complications / operated wound, mostly home treatment is done (especially Ash, Ghee, Moso \& Dew drops ) in the community. Modern medicinal ointments and oral tabs/ caps/ injection have been used very little as reported by households. In a community-based study conducted in Philippines (semi-structured face to face interview with 114 circumcised males) six of every 10 respondents (59.6\% or 68 of 114) reported having post-circumcision penile complications (inflammation and swelling), while four (40.4\%) had none. Almost all (60 of 68) did not consult their circumcisers about their penile complications. The rest $(n=60)$ self medicated. The healing period was from less than 1 week to 2 months.

Study also found that about $91 \%$ households now are agree to circumcise in hospital for quick healing with the services from health workers and sterilization facilities available in health institution. About 52\% of those out of agreeable opinions on hospitalization of circumcision recommend for the need of Muslim health workers and remaining recommended that they were okay with any health workers.

Their recommendation for Muslim health workers might be due to their strong conviction in religion and the holy statement (Bismallaha) that they have to rote during circumcision.

Regarding benefits study depicts that religious health as the main ( as reported by about $33 \%$ of households ) followed by hygiene and sexual satisfaction. Some reported only one and some even all the three benefits for circumcision. Study conducted in other countries also shows that these benefits and even to be physically fit and to cause pregnancy have been reported as benefits of circumcision as reported in community based study conducted in Philippines.

Religious faith, tradition and compulsion are the major reasons for circumcision as per the respondents' opinion in the sampled households. This was also found through natural group discussion that because of low awareness and level of knowledge among community people, the practices is not hygienic and aseptic. Lack of ideas among Muslims may be the reason for continuation with the Hazam. Hazam has become like an occupation, which generally goes generation to generation in a single family.

The principal reasons given for circumcision were " to improve penile hygiene" ( $89.1 \%)$, followed by 'to reduce peer pressure "' ( $6.2 \%)$ and "to improve future sexual potency" ( $2.1 \%$ ) in a study conducted in South Korea.

Looking at their opinion regarding appropriate circumciser and appropriate decision maker, it seems lack of ideas, resources and provision of the services from health service organizations as well as lack of effective sensitization programs that has made them follow the same practice under the same environment ( unskilled Hazam, home treatment with Ash, Moso, and Ghee ).

But one of the community based study conducted in South Korea ( 1674 responded included in the study ) showed that the decision of the child should be most important (circumcised versus uncircumcised men; $81.3 \%$ versus $88.0 \%$ ). Only 156 ( $9.3 \%)$ responded that the 
advice of the healthcare providers would be the most important in deciding whether to circumcise or not.

Majority of Muslim said during natural group discussion that they would readily accept if service is provided to them under health institution by health workers (preferably Muslim) or as a camp of circumcision annually or every 2 years.

\section{Reference:}

1) Wallerstein E. Encyclopaedia Americana (online) 1984 (cited 2005 May 7); 6:735. Available from: www.nocirc.org/articles/encyamer.php

2) Sansal B. Circumcision (online) 2003 ( cited 2005 May 9). Available from: www.allaboutturkey.com/sunnet.htm\#top

3) Williams N, Kapila L. Complications of circumcision. Brit J Surg 1993; 80:1231-6.

4) Morris BJ. Benefits of Circumcision: Medical, Health and Sexual (online) n.d (cited 2005 May 9). Available from: www.circinfo.net /index.html

6) Circumcision practices around the world: Circumcision Performed as a Religious Rite (Judaism and Islam) (online) (cited 2005 May 11). Available from: www.circumcisioninfo.com/circ world.html

7) Hill G. The Rise and Fall of Neonatal Circumcision: The irrational abuse of helpless

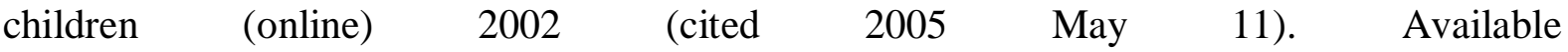
from:www.purewatergazette.net/circumcision.htm 